\title{
Mulheres com deficiência e sua dupla vulnerabilidade: contribuições para a construção da integralidade em saúde
}

\author{
Women with disabilities and their double vulnerability: \\ contributions for setting up comprehensive health care practices
}

Stella Maris Nicolau ${ }^{1}$

Lilia Blima Schraiber ${ }^{2}$

José Ricardo de Carvalho Mesquita Ayres ${ }^{2}$

${ }^{1}$ Universidade Federal de São Carlos. Rod.

Washington Luiz $\mathrm{km} 235$.

13565-905 São Carlos SP vawbr@usp.br

${ }^{2}$ Faculdade de Medicina,

Universidade de São Paulo.
Abstract Women with disabilities have few measures geared to their needs in the primary health care services. Despite the attention given to the female population in these facilities, they still fail to address specificities of women with disabilities, such as issues related to their sexual and reproductive rights and their double vulnerability, both as women and as disabled individuals. This research is part of a qualitative study to identify the individual, social and programmed double vulnerability of fifteen women with different types and degrees of disabilities, who are frequenters of three primary health care facilities in São Paulo city. The women's narratives highlighted experiences of rejection or overprotection in their family relationships, difficulties in obtaining equipment for their autonomy, poor education and lack of professional qualification, lower social participation, obstacles in their sex lives and motherhood. They face physical and communication barriers and poor care from primary health care services. All of the dimensions of vulnerability are present and addressing them makes it possible to build comprehensive health care practices that ensure the human rights of groups that historically experience violations, namely women and disabled persons.

Key words Gender and disability, Disabled persons, Comprehensive health care, Women's health, Vulnerability
Resumo Mulheres com deficiência contam com ações inexpressivas nos serviços de atenção básica em saúde, que embora historicamente privilegiem a clientela feminina, pouco reconhecem os aspectos relativos aos direitos sexuais e reprodutivos è dupla vulnerabilidade que as acometem por serem mulheres e portarem deficiências. Este estudo é parte de uma pesquisa qualitativa que objetiva identificar dimensões individuais, sociais e programáticas da dupla vulnerabilidade de quinze mulheres com diferentes tipos e graus de deficiência, usuárias de três serviços de atenção básica em saúde na cidade de São Paulo. Destacam-se em suas narrativas vivências de rejeição ou superproteção familiar, dificuldades em adquirir equipamentos para sua autonomia, pouco investimento no estudo e na qualificação profissional, menor participação social, obstáculos à vivencia da sexualidade e da maternidade, falta de acessibilidade física, comunicacional e atitudes pouco receptivas nos serviços de saúde, caracterizando total vulnerabilidade. Problematizá-la possibilita a construção de práticas integrais de saúde que incorporem a dimensão dos direitos humanos de grupos que historicamente experimentam a violação dos mesmos: mulheres e pessoas com deficiência.

Palavras-chave Gênero e deficiência, Pessoas com deficiência, Atenção integral à saúde, Saúde da mulher, Atenção primária à saúde, Vulnerabilidade 


\section{Introdução}

Mulheres com deficiência estão presentes em todas as faixas etárias, etnias, raças, religiões, estratos econômicos e orientação sexual. Historicamente ficaram à margem do próprio movimento de mulheres e do movimento pelos direitos civis das pessoas com deficiência ${ }^{1-3}$.

No Brasil, segundo dados do Censo de 2000, $14,5 \%$ da população brasileira referiu ser portadora de algum tipo de deficiência, sendo que $53,58 \%$ desta população é do sexo feminino. Entre as pessoas com mais de 60 anos, 49,64\% declararam ter alguma deficiência, e entre crianças até quatro anos essa cifra é de 2,26\% ${ }^{4}$. Isto revela que o acúmulo dos anos de vida tem estreita relação com a aquisição de deficiências, e se for considerado que a esperança de vida para as mulheres é maior do que para os homens, mesmo sob iguais condições socioeconômicas ${ }^{5}$, é possível afirmar que a questão da deficiência tende a ser uma relevante problemática de saúde coletiva e de saúde da mulher ao longo de seu ciclo de vida. Trata-se de um segmento da população que conta com ações inexpressivas voltadas para as suas necessidades nos serviços de atenção primária em saúde, que embora historicamente privilegiem a clientela feminina ${ }^{6,7}$, pouco reconhecem os aspectos relativos aos direitos sexuais e reprodutivos e à dupla vulnerabilidade que as acometem por serem mulheres e portarem deficiências. Esta condição é corroborada na literatura internacional sob a perspectiva da desvantagem $^{8}$ : as mulheres com deficiência apresentam duas desvantagens na vida social.

Trabalharemos essa dupla desvantagem pelo conceito de vulnerabilidade ${ }^{9}$. Este permite abarcar diferentes dimensões da experiência vivida relativamente às necessidades de saúde e à atenção dos serviços. Essa dupla vulnerabilidade da mulher com deficiência será discutida com base na integralidade em saúde, já que este princípio levaria as práticas a oferecerem respostas mais abrangentes às necessidades de saúde, abordando-as de modo mais holístico, ao articular a dimensão curativa à prevenção e à promoção da saúde. A integralidade designa um conjunto de valores pelos quais o movimento social em saúde lutou e pretende lutar; uma imagem-objetivo das características desejáveis do Sistema Único de Saúde ${ }^{10-12}$.

No plano das práticas profissionais, a integralidade diz respeito a uma boa prática que se inicia pela apreensão ampliada das necessidades no encontro profissional-usuário, a partir de um olhar atento às demandas referidas e também àquelas ainda não referidas, mas passíveis de uma ação preventiva ou de um diagnóstico precoce ${ }^{11,13}$. E, nesse sentido, a integralidade funcionará para a atenção primária à saúde não apenas como modo assistencial de responder às demandas dos usuários, mas como 'contexto instaurador de novas necessidades de saúde ${ }^{13}$, dando, desta forma, visibilidade a questões socioculturais abandonadas pela redução biomédica na assistência médica individual 5 .

Operar com a integralidade representa a aproximação mais fecunda para explorar as situações de vulnerabilidade a que as mulheres com deficiência estão submetidas, invisíveis aos serviços de saúde pela ausência de sua abordagem pelos profissionais.

A dupla vulnerabilidade dessas mulheres é discutida pelos estudos sobre a deficiência (disability studies) que surgem nos anos 1970, no Reino Unido e Estados Unidos. Analogamente ao feminismo, concebem a deficiência como uma forma de opressão sofrida por uma diferença corporal e que deve ser combatida. Diferenciam, pois, como nos estudos feministas, a condição natural de lesões, de uma construção sociocultural que necessariamente a vê como deficiência ${ }^{14}$.

Já estudos feministas sobre a deficiência ( $f e$ minist disability studies) emergem em um segundo momento e apresentam convergências e divergências em relação aos disability studies. As convergências dizem respeito à definição de deficiência como um fenômeno sociológico e ao fato da subalternidade dos deficientes não poder ser explicada somente pela presença de uma lesão, mas pelos obstáculos que enfrentam na vida social e política. As divergências referem-se às demandas e aos diferentes pontos de vista em relação à experiência da deficiência: os primeiros teóricos eram em sua maioria homens com deficiências motoras que lutavam pela independência e inserção no mundo do trabalho a partir da retirada das barreiras sociais que os impediam de exercer um papel produtivo. As teóricas feministas (em geral mulheres com deficiência) buscam revelar como o gênero opera no universo da deficiência ${ }^{15}$ e também passam a dar visibilidade ao trabalho das cuidadoras das pessoas com deficiência mais gravemente acometidas.

De um lado, postulam que todos somos "corpos temporariamente aptos", sendo poucas as fases da vida em que não necessitamos de cuidado ou apoio social ${ }^{14}$. De outro, analisando as representações culturais em relação às mulheres com deficiência e por estarem implicados com o 
ativismo político, buscam recuperar a identidade feminina que a cultura lhes nega, além de uma política que preserve o direito de definirem suas diferenças físicas e sua feminilidade por si mesmas, ao invés de receberem interpretações de outros sobre seus corpos ${ }^{15,16}$. Também buscam identificar e denunciar o modo discriminatório com que os estudos científicos, sobretudo aqueles do campo da medicina, referem-se tanto às mulheres como às pessoas com deficiência, considerando-as semelhantes: puro corpo, objetos do olhar fixo e do espetáculo que pode ser tanto a exposição das aberrações nas atrações circenses como os concursos de beleza e a exposição do corpo da mulher na mídia ${ }^{15}$. Além disso, apontam que a mulher é definida como uma versão inferiorizada do corpo masculino. Essa concepção é reiterada nos estudos médicos a partir do século XVIII, quando a medicina se apodera do corpo feminino para responder aos interesses demográficos da sociedade moderna capitalista ${ }^{17}$.

Nessa perspectiva, o corpo da mulher e da pessoa com deficiência deve ser regulado pelas políticas de medicalização através de procedimentos disciplinares para sua normalização, como as cirurgias corretivas e as políticas de aparência que sustentam a instituição do cosmético e da cirurgia plástica, pois, a beleza, em nossa sociedade, consiste em um sistema de valor, uma ideologia cultural coercitiva que relaciona determinada aparência corporal como pré-requisito para ganhar amor, status e reconhecimento, e revela o paradoxo de que a mulher emancipou-se politicamente, mas não se liberou do mandato social de perseguir beleza ${ }^{15}$.

Dois eixos enfatizados na reflexão feminista são a discriminação socioeconômica (mulheres com deficiência trabalham em ocupações menos qualificadas e recebem menos do que homens com deficiência e mulheres sem deficiência) e a excessiva medicalização da deficiência, que vê esta condição como doença ${ }^{1,2,18}$.

Tendo em vista os poucos estudos sobre mulheres com deficiência no Brasil, realizamos uma pesquisa em serviços de atenção primária, em que profissionais e mulheres usuárias com deficiência foram investigados. Objetivamos conhecer como essas mulheres faziam uso desses serviços, examinado-lhes a condição de ser mulher e ser portadora de deficiência, tendo em vista o próprio conjunto de necessidades que reconheciam como suas; e como, segundo elas e também segundo os profissionais, foram acolhidas e cuidadas. Para tal, a pesquisa produziu dados em três direções: as necessidades identificadas pelas mulheres com deficiência, a resposta dada pelos serviços a essas necessidades e a relação estabelecida entre as mulheres e os serviços facultando tal ou qual modo de uso dos mesmos. Deste conjunto, abordaremos aqui o ponto de vista das mulheres, quanto às suas situações de vida em que as necessidades de saúde são geradas, ao reconhecimento destas e ao modo como se relacionam com os serviços de atenção primária dos quais são usuárias.

\section{Metodologia}

Buscamos uma aproximação que desse voz a mulheres com deficiência usuárias de três distintas unidades básicas de saúde localizadas na região oeste da cidade de São Paulo. Esses serviços integraram um subprojeto da pesquisa "Caminhos da Integralidade: levantamento e análise de tecnologias de cuidado integral à saúde em serviços de atenção em região metropolitana”, aprovada pelos Comitês de Ética em Pesquisa da Universidade e da Secretaria Municipal de Saúde.

Os três serviços ora considerados seguiram critérios dessa pesquisa maior, e, adicionalmente, o fato de terem usuárias mulheres com deficiência, pois representaram a forma de captação de usuárias a serem entrevistadas e o contexto de atenção primária concretamente por elas utilizado. As entrevistas ocorreram entre 2009 e 2010, totalizando 15 usuárias (cinco de cada serviço).

Recrutamos mulheres na faixa etária reprodutiva, ou próxima, e com deficiências variadas: visual, auditiva, intelectual e motora; congênitas ou adquiridas. A idade variou entre 19 a 54 anos, sendo que 11 entrevistadas tinham 30 ou mais anos. Essa faixa etária permitiu explorar questões da autonomia, sexualidade, trabalho, casamento e maternidade. Quanto à diversidade das deficiências, não foi possível encontrar mulheres com deficiência auditiva, o que pode ser consequência da presença menor desses casos na atenção primária.

Para encontrar as usuárias, contamos com a indicação dos profissionais dos serviços e também com a indicação das primeiras mulheres entrevistadas. Foi realizado contato telefônico ou visita domiciliar para realizar o convite e agendar o encontro que poderia ocorrer em data e local mais conveniente para a entrevistada.

As mulheres com deficiência intelectual ou com dificuldades de comunicação verbal foram entrevistadas juntamente com suas cuidadoras, que em três situações foram suas mães e em um caso 
a irmã. Houve uma entrevista que foi realizada somente com a cuidadora (mãe) pelo fato de se tratar de pessoa com quadro severo de deficiência motora associado à deficiência intelectual.

As entrevistas foram do tipo semiestruturado, gravadas e posteriormente transcritas com conferência de fidelidade e totalizaram cerca de 10 horas, com uma média de 40 minutos cada entrevista. Os nomes citados são fictícios.

Para a análise dos dados, usamos o referencial da vulnerabilidade, definida como "resultante de um conjunto de fragilidades individuais e precariedades sociais que atingem um sujeito cujas condições de vida e saúde são influenciadas ou determinadas pelo social e pela história"19.

Ou como esclarece Ayres ${ }^{12}$ :

"De modo sumário, os estudos de vulnerabilidade buscam compreender como indivíduos e grupos de indivíduos se expõem a dado agravo à saúde a partir de totalidades conformadas por sínteses pragmaticamente construídas com base em três dimensões analíticas: aspectos individualizáveis (biológicos, comportamentais e afetivos), que implicam exposição e suscetibilidade ao agravo em questão; características próprias a contextos e relações socialmente configurados, que sobredeterminam aqueles aspectos e, particularizando a partir destes últimos, o modo e o sentido em que as tecnologias já operantes nestes contextos (políticas, programas, serviços, ações) interferem sobre a situação - chamadas, respectivamente, de dimensão individual, social ou programática”.

Nossa análise adota as três dimensões de vulnerabilidade referidas pelo autor, examinando as situações de vulnerabilidades em que nossas mulheres estão inseridas e interpretando suas percepções acerca dessas situações.

\section{Resultados e discussão}

Das quinze mulheres entrevistadas, oito nasceram com uma deficiência ou a adquiriram ainda na primeira infância, antes dos dois anos de idade, e sete delas adquiriram a deficiência no decorrer do ciclo da vida, seja no início da adolescência ou na idade adulta. Embora haja diferenças significativas entre conviver com uma deficiência congênita e com uma deficiência adquirida, os relatos apontam esforços adaptativos importantes para lidar com esta situação nos dois grupos de mulheres.

Pode-se apreender a dimensão individual da dupla vulnerabilidade dessas mulheres pelas ex- periências de superproteção ou rejeição familiar, pela falta de acesso a serviços de saúde e reabilitação, pela privação de recursos materiais que impediu ou dificultou a aquisição de equipamentos que garantissem maior autonomia, pela falta de investimento em sua educação e habilitação/ reabilitação profissional, e, pela vivência em um meio familiar com atitudes hostis e que desqualificam mulheres e pessoas com deficiência.

Neusa (50 anos, deficiência motora) e Miriam (39 anos, deficiência intelectual) nasceram em área rural, nunca frequentaram serviços de reabilitação, cresceram em famílias com poucas informações sobre a deficiência, em uma cultura tradicional de gênero e paternalista. Neusa recebeu sua primeira cadeira de rodas aos 13 anos, idade com a qual ingressou na escola, onde permaneceu por pouco tempo. Adriana (33 anos, deficiência motora) adquiriu artrite reumatoide aos 10 anos e abandonou a escola pela dificuldade de locomoção. Luciana (32 anos, deficiência motora) por sua vez, recebeu grande investimento em sua reabilitação e escolarização por parte da família, mas revela que a superproteção por parte dos familiares tolheu sua autonomia, pois por ter baixa estatura e fragilidade óssea, sempre foi tratada por estes como uma criança indefesa, mesmo após a idade adulta:

Porque a minha infância foi muito regrada, muito cuidada, muito mimo. Então eu sempre tive a família presente até demais. Eu fui o tempo todo cuidada como uma boneca de louça pela minha deficiência e isso me prejudicou no desenvolvimento. Apesar que também eu sou uma pessoa muito alegre, muito enérgica, muito disposta e tenho uma vontade de viver muito grande, eu sempre, sempre fui bem precoce, aí com cinco anos eu estudei em colégio regular, [...] e foi o melhor momento da minha vida que eu convivia com crianças que não tinham deficiências e eu me sentia super bem, mas por um lado, ainda era aquela situação, que eu não me assumia como pessoa com deficiencia, $e$ das limitações e dos deveres. Eu achava que ia ter uma coisa, que ia acontecer alguma coisa que eu ia ficar diferente, sabe, no fundo, no fundo talvez tivesse um pouco isso. E a minha família sempre me superprotegeu (Luciana).

Via de regra, portanto, a maior autonomia raramente foi buscada pelos familiares, como no caso de Fernanda (39 anos, deficiência motora) que frequentou instituição educacional especializada na infância e início da adolescência, abandonando-a sem concluir o ensino fundamental, com anuência da família, como igualmente relata Renata (43 anos, deficiência visual): 
Aí eu vim morar aqui com seis anos, nesse lugar aqui [...] que daí as freiras do colégio que tinha aqui atrás elas sempre me observavam brincando lá da janela e era muito difícil porque tinha muito buraco, muito morro e elas ficavam me olhando e vieram aqui em casa, conversaram com a minha mãe e arrumaram um colégio pra mim estudar lá no Ipiranga, no Instituto Padre Chico e condição eu não tinha mas elas me deram tudo porque pra ir pra lá precisava levar tudo, eles davam só comida, cama e o estudo. Eu tinha que levar praticamente um enxoval, toda a roupa, toda a roupa de cama, o material pra estudar eles me deram tudo [...] Eu ficava lá com todas as outras pessoas, tinha muita gente lá. [...] Eu fui com quase sete anos [para lá]. Lá eu aprendi muita coisa, tinha natação e depois eu comecei a aprender o braile [...], eu vinha todo final de semana [para casa], era obrigatório, mas tinha muita gente lá que ia pra casa só nas férias, que morava muito longe, em outros estados, mas era bom. Eles levavam a gente pra passear, levavam a gente nos parques, nas bibliotecas, levavam até na praia. [...] O tempo de ficar assim, longe de casa no começo era ruim, mas depois eu fui me acostumando e eu gostava de ficar lá. [...] [Eu saí de lá] porque lá quando a gente entrava na quinta série, eles começavam a ensinar locomoção e eu coloquei na minha cabeça que eu não queria fazer, não queria andar de bengala, que, sei lá, o negócio não combina comigo. [...] E minha família também não fez nada pra que eu mudasse de ideia, apoiou o que eu escolhi.[...] Eu acho que eu não tenho habilidade, é claro que eles iam ensinar tudo $e$ inclusive hoje tem pessoas que estudaram junto comigo que eu conheço que tem uma vida ativa, trabalham, que vão pra aonde querem, que saem, viajam sozinhos. [...] Eu acho que eu perdi muito da minha vida, que eu podia ter uma vida completamente diferente e hoje eu penso assim que eu nunca posso fazer tudo o que eu quero, na hora que eu quero, eu sempre tenho que precisar de alguém. [Minha dependência é] pra sair de casa porque aqui dentro pra mim é normal, eu faço tudo, eu vou no portão, eu vou em qualquer lugar aqui [...], o problema é na rua, e eu não consigo andar na rua do lado de uma pessoa, eu não consigo. Eu tenho que segurar na mão ou no braço. Se eu não segurar eu não me sinto segura (Renata).

A dimensão social da dupla vulnerabilidade das mulheres com deficiência diz respeito a vivências em um meio social no qual mulheres e pessoas com deficiência têm uma posição social menos qualificada e experimentam menores possibilidades de participação social e política, acesso à educação, à justiça, à saúde, ao trabalho regulamentado, a benefícios sociais, à cultura, ao lazer e demais bens sociais que promovam a equidade de gênero e o desenvolvimento humano de pessoas com deficiência.

A acessibilidade é o princípio de tudo, porque sem acessibilidade eu não tenho educação, sem acessibilidade eu não tenho saúde, sem acessibilidade eu não tenho esporte, não tenho lazer, não tenho nada. Então eu acredito que a acessibilidade é o fundamental pra um deficiente porque ele começa na acessibilidade saindo do portão da casa dele, então ele vai encontrando obstáculo pra todo lugar. Dependendo do deficiente, se ele não conseguir pegar um [ônibus] adaptado e não tiver adaptado na linha, ele não vai a lugar nenhum. Então eu acho que acessibilidade é o início do caminho de um deficiente. [...] Por exemplo, eu saio daqui, eu vou num teatro; eu chego lá no teatro, ele tem uma peça maravilhosa que eu quero assistir, só que tem uma escadaria imensa [...] Eu vou chamar, vou procurar o segurança, o responsável da área, vou chegar e vou falar: "olha, eu quero assistir, como é que a gente faz?". Outro dia eu fui numa peça de teatro aqui na Paulista e eles colocaram umas barra lá em cima[...] Eu fui com [um amigo], nós dois cadeirantes. Aí o segurança catou a gente lá em cima, eles fizeram uma barra, umas barras de ferro porque os cadeirantes fica ali, então, quer dizer, aquelas barra fica na frente do olho da gente. A distância é muito longe pra enxergar (Neusa).

Chama a atenção nos relatos o fato de que poucas entrevistadas entraram no mercado formal de trabalho, sobretudo aquelas com deficiência congênita. Todas encontravam-se sem emprego, algumas vivendo do benefício de prestação continuada do INSS e/ou realizando trabalho informal, tal como confecção de artesanato, venda de produtos, prestação de serviços. Outras dependiam financeiramente de seus familiares e, Luciana, por exemplo, jornalista e única com curso universitário, buscava emprego na sua área. Mas referiu que as editoras não estão dispostas a adaptar seu espaço físico para empregar cadeirantes, e já foi empregada em funções aquém de sua qualificação profissional, além de alocada em postos de trabalho nos quais ficava 'escondida', considerando isso um tipo de discriminação.

Algumas mulheres enfrentam preconceitos para viver a sexualidade e a maternidade, na medida em que habitam um corpo que destoa dos padrões estéticos vigentes e enfrentam a descrença da sociedade de que possam corresponder às expectativas de gênero, como assumir os papéis de cuidadora, esposa e mãe. 
Aí os meus irmãos [...] começaram a dizer que a minha gravidez era psicológica; que eu não ia engravidar nunca. Imagina, que eu era tão louca pra engravidar e pra ser mãe, que eu tava com gravidez psicológica. Daí eu fui, peguei o resultado, mostrei pro meu marido, li, ficou feliz também, mas não mostrou aquela felicidade... aquela coisa... que, de repente, talvez até ele mesmo duvidasse disso, porque se ele não duvidasse, ele ia tá ali, vibrando junto, daí eu segurei. Quando os meus irmãos viram a minha barriga, e que eu tava grávida realmente, começaram a falar que o meu filho podia nascer aleijado igual eu, se eu já tinha pensado nessa possibilidade, porque eu tava sonhando muito alto, e eu era a grávida mais coruja do mundo, eu conversava com o meu filho o tempo todo na minha barriga, e eles ficavam: "você só tá pensando no melhor, você não sabe o vai acontecer; e se essa criança vim aleijada como você?’"...] O primeiro dia que eu fui fazer o exame de gravidez, o meu exmarido me levou [...] Quando eu saí, o médico fez eu voltar e perguntou o que tinha acontecido comigo. Daí eu falei que era pólio; daí, pelo espanto dele, eu fiquei preocupada, ai eu perguntei se tinha alguma coisa; ele falou que não, se fosse de nascença, sim, mas a pólio não tinha nenhuma interferência, então eu fiquei tranquila. E, depois que eu fiquei na gravidez do filho, a gravidez dos nove meses, eu tive uma gravidez maravilhosa, nunca tive problema nenhum na gravidez [...] [O parto] foi cesária, porque ele era muito grande, eu era muito pequeninha... E, eu sei que próximo do meu bebê nascer, cada um falava uma coisa, teve um dia que eu entrei na paranoia e chorei o dia inteiro, porque eu tinha preparado o berço do nenê, pra me internar e chegar com ele todo bonitinho, e não sei quem que falou se eu já tinha pensado na possibilidade desse nenê não vir aqui pra casa. Ele podia nascer morto, podia ficar por lá mesmo, então quer dizer, eu me tranquei naquele dia, eu chorei que nem louca, então eu fiquei o dia inteiro desesperada. Aí, quando o meu marido chegou, aí ele falou "não pensa besteira, não é por aí as coisas"; daí eu levantei e continuei de cabeça erguida. Até que, ele nasceu, nasceu um menino muito grande, bonito (Neusa).

A experiência da maternidade para algumas mulheres com deficiência possibilita a "recaptura" da identidade feminina perdida. Entretanto, elas relatam empreender grandes esforços para corresponder às expectativas sociais de serem mães adequadas, pois, como bem mostrou Neusa, enfrentam o ceticismo do meio social quanto às suas capacidades de gerar e cuidar de um filho ${ }^{20}$.

As mulheres com deficiência intelectual, como Tainá e Miriam, relatam o desejo de ter uma rede social que possa proporcionar-lhes lazer, diversão e possibilidade de relacionamentos afetivosexuais, o que é corroborado pela ausência de espaços de convivência que sejam receptivos às pessoas com deficiência intelectual fora das instituições especializadas. As cuidadoras se queixam que os familiares não se envolvem nessas demandas e por isso elas se sentem sozinhas para responder a todas essas necessidades.

A dificuldade em acessar os direitos está relacionada à dimensão social da vulnerabilidade. Embora o Brasil conte com um importante aparato jurídico para promover a equidade de gênero e a inclusão de pessoas com deficiência na vida social, a realidade apresentada pelas entrevistadas ainda é marcada por iniquidades.

O Brasil é signatário desde 2008 da Convenção dos Direitos das Pessoas com Deficiência, um tratado internacional de direitos humanos com maior força jurídica vinculante que os anteriores, e que representa um marco na mudança de paradigma em relação às pessoas com deficiência, pois rompe com uma abordagem baseada na assistência e incorpora a dimensão dos direitos, especialmente os civis e os políticos ${ }^{21}$.

Das mulheres entrevistadas somente três delas apresentam um discurso sobre si no qual se reconhecem como cidadãs, pessoas com direitos e responsabilidades, e que se engajaram em movimentos em prol das pessoas com deficiência. Duas delas citam a Convenção, mas ainda com certo ceticismo em relação ao seu cumprimento.

Agora a partir de agora o Brasil é obrigado a cumprir a Convenção, o que significa isso, que todas as leis federais, estaduais e municipais têm que seguir a Convenção. Mas a gente sabe que isso não acontece porque hoje de todas as leis, a única que existe sanção, que tem multa mesmo é a lei de cotas das empresas. As demais leis de acessibilidade, por exemplo, que os postos de saúde sejam acessíveis, não existe multa, e não existe multa nem fiscalização. Tudo bem, o Brasil hoje é um dos países que tem uma das melhores legislações em relação à pessoa com deficiência, um dos melhores mesmo, comparado até aos Estados Unidos, o problema é que não tem fiscalização (Luciana).

As demais associam seus direitos às possibilidades de acessarem benefícios sociais, como a isenção na tarifa do transporte coletivo e o benefício de um salário mínimo do INSS caso vivam em situação de pobreza. Nesse sentido, reivindicam menos a participação política e mais uma ação assistencial do Estado em relação a elas.

Os direitos que até agora eu tive foi receber [...] Eu sou aposentada.[...] Fui [atrás disso] mais 
minha prima [ela me orientou] [...] Ela sabia, tem esse direito, aí dei entrada umas três vezes, fiquei pensando que eu não tinha direito, mas quando foi na quarta vez a gente conseguiu. [...] Eu acho que um direito é quando eu vou também andar nos ônibus, eles respeita é muito [...] Nem pago,e quando eu entro eles veem que eu tô dentro, eles já se levanta, me dão o assento. [...] Tenho carteirinha prá mim e o acompanhante (Marcia, deficiente visual)

Já a vulnerabilidade programática diz respeito à falta de políticas assistenciais que contemplem as especificidades das mulheres com deficiência, à falta de acessibilidade física e comunicacional nos serviços regulares de saúde - como as unidades básicas de saúde, ambulatórios e hospitais - à falta de sensibilização e capacitação dos profissionais de saúde, à falta de reconhecimento nos serviços dos direitos humanos das mulheres com deficiência, a fim de protegê-los e promovê-los, como bem relata Neusa:

E o papanicolaou até hoje a gente tem problema porque a sala de gineco é lá em cima, tem escada, e eu já fiz entrevista com o pessoal do serviço, veio um grupo aqui uma vez olhar a acessibilidade e a gente questionou isso. Aí teve uma época que como eu era conselheira do conselho de saúde aqui [da região], [...] que a gente batalhou isso porque tinha, a gente brigava muito, dai a gente conseguiu junto com a subprefeitura uma sala embaixo. Como eu sempre atuei na parte de acessibilidade eu testei a maca do gineco, tinha que cortar, porque daí eu pedi essa sala prá deficiente, idoso e obeso, e eles fizeram tudo bonitinho, só que assim, eu fiz um exame só e não fui mais, aí o pessoal falou que ia tirar porque os deficientes não tavam usando.[...] Agora tá assim, agora tem um grupo do PSF, acho que tá melhorando que eu espero que ele continue. Só que eu não tenho feito o papanicolaou agora com esse grupo. Só que a última vez que eu fui no posto, antes de implantar o PSF, foi o maior show porque a médica não quis colher o meu papanicolaou. Por que tem uma lei que obriga o médico a descer se o deficiente tá aqui embaixo ele tem que descer, porque eu não posso subir até ele de escada. Aí ela desceu, só que não tinha maca pra colher o papanicolaou. Ai eu fiz o maior show. "Cadê? Tem. Eu acompanhei e essa maca existe! Prá onde que ela foi?" Daí chamaram a diretora do posto, a diretora veio toda preocupada, como que ia fazer, daí a médica disse: "Ó se você quiser nós pede pro segurança levar você lá encima”. Eu falei "não, meu filho tá aqui comigo, só que eu não quero ter que subir lá encima, eu quero o direito de ser atendida aqui embaixo. Esse é o meu direito, então eu quero ser atendida aqui, eu não vou subir". Aí a diretora veio, acharam, a maca tava enfiada dentro de um depósito lá com um monte de coisa, tiraram a maca, limparam, passaram álcool na hora e me atenderam. Esse dia eu fiz, daí o meu filho falou "mas cê gosta de causar". Não é que eu gosto de causar, ela tava aí, eu pedi, e não sou só eu que preciso. Tem muitos deficientes no bairro, tem idoso, tem obeso, só que aí agora eu não tenho acompanhado mais (Neusa).

Luciana relata o quanto os profissionais são despreparados em relação às questões ligadas à sexualidade das mulheres com deficiência. Por outro lado, das 15 mulheres entrevistadas, cinco são separadas (três após a aquisição da deficiência), duas são casadas e oito são solteiras. Oito mulheres não têm filhos e sete são mães de mais de um filho. Das sete mulheres com filhos, três tiveram filhos após a aquisição da deficiência, o que corrobora o fato de que mulheres com deficiência querem ter vida sexual ativa e necessitam de atenção em relação à sua saúde sexual e reprodutiva.

A primeira ginecologista que eu fui que foi uma pessoa da família [...] tive uma experiência em relação à ginecologia muito triste. Eu fui numa médica indicada pela família, na verdade eu fui leva$d a$, na verdade eu fui carregada, nem me falaram direito o que era. [Tinha] dezenove anos [...] quando eu comecei a namorar um garoto com 18-19 anos, quando minha família ficou sabendo, ficaram desesperados, aí me levaram no médico e foi uma situação horrível, porque a ginecologista colocou um livro de anatomia na minha cara, olhou e falou, tá vendo isso daqui, você não pode usar! Falou assim: 'olha, você tem tudo igual, você sabe o que é o aparelho reprodutor? Então você tem que saber que você não pode fazer nada com o seu corpo. Foram essas as palavras que ela usou.[...] [Quem me levou] foi uma tia da família. Uma senhora de idade, com uma certa preocupação, lógico, mas, é importante registrar isso porque assim, independente da situação da família, a profissional em nenhum momento poderia ter agido dessa forma. Em nenhum momento! Nem que a família tivesse falado pra ela: 'Faça assim! Fale desse jeito', ela teria que conversar com a família e falar 'eu enquanto profissional não posso ser antiética, não posso agir dessa forma'. Então, assim, me traumatizou muito. [...] Foi uma situação chatíssima, muito dolorosa, porque eu fui pensando que eu ia esclarecer dúvidas, porque eu tinha um monte de pergunta, e assim: não pediu nenhum exame, nem sequer pensou na minha situação de saúde. Não pediu nada. Não pensou na questão da saúde, só 
pensou na questão da relação sexual. Que eu nem sonhava ainda!! Porque eu ainda tava no começo do namoro, sabe, ainda tava em beijos e abraços, imagina, não tinha uma coisa, e se tivesse eu iria perguntar, eu nunca iria fazer nada, porque eu sou uma pessoa muito responsável, até demais, e mesmo assim não justifica uma atitude dessas. [...] Eu quando fui no médico agora que eu te falei que fiz os últimos exames, foi um homem. O cara não quis nem tocar em mim. Ficou olhando assim, parecia que ficou assustado, aí timidamente ele perguntou, depois que perguntou das partes de saúde e tal, falou dos exames, aí ele perguntou: 'Ah mas você usa preservativo? cê toma pílula? não sei o que. Em vez dele logo falar 'você tem vida sexual ativa?' Como é que faz, tem algum problema, tem alguma dúvida, tá precisando de alguma coisa? (Luciana)

Outro aspecto levantado diz respeito à atitude do serviço em relação às mulheres com deficiência, como a falta de prioridade no atendimento, o despreparo e a falta de interesse dos profissionais às suas demandas específicas.

Falta um pouquinho de preparação [...] ele devia perguntar: “- É cadeirante? Não é?” Ver se o Posto, às vezes, pode atender.[...] Eu acho que [o serviço não se empenha] porque [...] chega lá, ela é deficiente, ela não anda, tem problema mental, ela não tem tolerância a chegar num Posto de Saúde e ficar esperando todo mundo passar pra depois chegar a vez dela. Ela não. Ela já quer passar [...] Ninguém passa ela na frente. Tem que aguardar lá. Esperar. Eles não passam [...] Teve uma vez lá que ela começou a ficar nervosa, começou pedir: "- Eu quero ir embora. Eu quero ir embora. Eu quero ir embora." Aí eu tive que pedir pra pessoa que tava na frente, deixar eu passar ela porque... Aí eu falei com o médico e o médico passou. Porque o [atendente] lá da frente, eles não colocam, assim, a ficha dela. Aí ela fica, ela não tem paciência de chegar e esperar. Aí já começa: “- Eu quero ir embora. Eu quero ir embora." E já começa. Começa a beliscar, apertar a gente, agarrar as pessoas que passam. E fica assim. (mãe da Diana).

\section{Considerações finais}

Retomando a discriminação socioeconômica e a excessiva medicalização da deficiência enquanto os dois eixos enfatizados pela literatura no estudo das mulheres com deficiência, constatamos o quanto estão presentes nas situações relatadas pelas nossas entrevistadas. Por outro lado, a identificação das diferentes dimensões da vulnerabilidade na experiência cotidiana dessas mulheres permite uma ampliação do nosso olhar para além de demandas relativas a alterações morfofuncionais de seus corpos, assim como para as distinções, que constituem efetivamente desigualdades, ou discriminações médico-sanitárias, inscritas em suas condições de usuárias de serviços públicos de atenção primária à saúde.

Tate e Weston ${ }^{18}$ e Rao apontam que as mulheres com deficiência sofrem discriminação em diferentes culturas e sociedades, sendo maior nos países mais pobres e geralmente incrustrada em valores tradicionais que restringem as chances de desenvolvimento pessoal às mulheres. As autoras apontam a necessidade de investimentos na educação e qualificação profissional das mulheres com deficiência a fim de que consigam autonomia financeira, além da necessidade de mudanças nas atitudes frente a elas, pois em algumas sociedades tradicionais as mulheres só adquirem uma maior participação na vida social após o casamento, e aquelas com deficiências geralmente experimentam o isolamento domiciliar desde a infância e na vida adulta são mais rejeitadas como esposas.

Acreditamos ser urgente, portanto, a instauração de outro olhar e outros contextos assistenciais, regidos por práticas de saúde ampliadas, para que os serviços e a equipe de seus profissionais possam se aproximar do conjunto diverso de questões que se situam nas necessidades de saúde dessas mulheres. Olhar para os seus contextos de vida faz com que as preocupações das práticas de saúde se voltem para dimensões da vida relacional dessas mulheres, captando com maior riqueza tanto aspectos psicossociais como socioculturais. Nesse sentido, abordagens concebidas a partir dos pressupostos da integralidade em saúde nos parecem as mais potentes no enfrentamento e superação das diversas vulnerabilidades às quais as mulheres com deficiência estão submetidas.

Um dos aspectos, porém, que ainda é pouco estudado e raramente detalhado nas formulações de uma atenção integral, é o da incorporação de conhecimentos, formas de identificação e ações de promoção dos direitos humanos e sociais nas práticas de saúde cotidianamente desenvolvidas nos serviços. Embora a pauta dos direitos seja sempre lembrada nas políticas de saúde e permeia o discurso programático da atenção integral $^{5,19}$, pouco se sabe acerca do modo como os direitos são articulados nos processos assistenciais e nas ações de prevenção ou promoção da saúde nos serviços.

O relatório sobre a situação mundial das pessoas com deficiência ${ }^{22}$ aponta três razões que jus- 
tificam a deficiência como uma questão de direitos humanos: a experiência da desigualdade no acesso a saúde, educação, emprego e participação política; uma maior sujeição a situações de violação da dignidade pelo abuso, violência, preconceito e desrespeito; e, a negação da autonomia das pessoas com deficiência quando sujeitas à esterilização involuntária, confinadas em instituições contra a sua vontade, e/ou vistas como legalmente incompetentes.

Não obstante, a questão dos direitos é muitas vezes tratada de modo reduzido a dificuldades de obtenção de alguns dos benefícios sociais, formulados pela legislação trabalhista ou outras de assistência social. O reconhecimento das iniquidades e sua correção pela afirmação dos direitos das mulheres com deficiência, nesta dupla situação de desigualdade, pouco se revela, ainda, como uma forma de corrigir, na saúde, as vulnerabilidades dessas mulheres.

\section{Colaboradores}

SM Nicolau, LB Schraiber e JRCM Ayres participaram igualmente de todas as etapas de elaboração do artigo. 


\section{Referências}

1. Lewis AN, Brubaker SJ, Armstron AJ. Gender and disability: a first look at rehabilitation syllabi and a call to action. Rev disabil stud 2009; 5(2):3-13.

2. Lloyd M. Does she boil eggs? Towards a feminist model of disability. Disabil Soc. 1992; 7(3):207-221.

3. Rao I. Equity to women with disabilities in India. Bangalore 2004; CBR Network. [acessado 2011 out 28]. Disponível em: http://v1.dpi.org/lang-en/resources/details.php? page $=90$

4. Neri M, Pinto A, Soares W, Costilla H. Retratos da deficiência no Brasil. Rio de Janeiro: Fundação Getúlio Vargas, Instituto Brasileiro de Economia, Centro de Políticas Sociais; 2003.

5. Figueiredo WS. Masculinidades e cuidado: diversidade e necessidades de saúde dos homens na atenção primária [tese]. São Paulo (SP): Faculdade de Medicina da Universidade de São Paulo; 2008.

6. Mota A, Schraiber LB. Atenção Primária no Sistema de Saúde: debates paulistas numa perspectiva histórica. Saúde Soc 2011; 20(4):837-852.

7. Gomes R, Moreira MCN, Nascimento EF, Rebello LEFS, Couto MT, Schraiber LB. Os homens não vêm! Ausência e/ou invisibilidade masculina na atenção primária. Cien Saude Colet 2011; 16(Supl. 1):983-992.

8. Hanna WJ, Rogovsky B. Women with disabilities: two handicaps plus. Disabil Soc 1991; 6(1):49-63.

9. Ayres JRCM, Calazans GJ, Saletti-Filho HC, FrançaJunior I. Risco, vulnerabilidade e práticas de prevenção e promoção da saúde. In: Souza GW, Minayo MCS, Akerman M, Drumond Junior M, organizadores. Tratado de Saúde Coletiva. Rio de Janeiro, São Paulo: Fiocruz, Hucitec; 2006: 375-417.

10. Mattos RA. Os sentidos da integralidade: algumas reflexões acerca de valores que merecem ser defendidos. [acessado 2011 jul 18] [cerca de 16p.] Disponível em: http://www.lappis.org.br/media/ artigo_ruben 1.pdf

11. Mattos RA. A integralidade na prática (ou sobre a prática da integralidade). Cad Saude Publica 2004; 20(5):1411-1416.

12. Ayres JRCM. Organização das Ações de Atenção à Saúde: modelos e práticas. Saúde Soc 2009; 18(Supl. 2):11-22.
13. Schraiber LB, Mendes-Gonçalves RB. Necessidades de saúde e atenção primária. In: Schraiber LB, Nemes MIB, Mendes-Gonçalves RB, organizadores. Saúde de adulto: programas e ações na unidade básica. São Paulo: Hucitec; 2000. p. 29-47.

14. Diniz D. Modelo social da deficiência: a crítica feminista. Brasília: Letraslivres; 2003. (Série Anis, n. 28).

15. Garland-Thomson R. Re-shaping, re-thinking, redefining: feminist disability studies. Washington: Center for women policy studies; 2001.

16. Fine M, Asch A, editores. Women with disabilities: Essays in psychology, culture, and politics. Philadelphia: Temple University Press; 1988.

17. Vieira EM. A medicalização do corpo feminino. Rio de Janeiro: Ed. Fiocruz; 2002.

18. Tate DG, Weston NH. Women with disabilities: an international perspective. Rehabil Lit 1982; 46(78):222-227.

19. Brasil. Ministério da Saúde (MS). Direitos sexuais e reprodutivos na integralidade de atenção à saúde de pessoas com deficiência/Ministério da Saúde. Secretaria de Atenção à Saúde, Departamento de Ações Programáticas Estratégicas. Brasília: MS; 2009.

20. Grue L, Laerum KT. "Doing motherhood": some experiences of mothers with physical disabilities. Disabil Soc 2002; 17(6):671-683.

21. Dhanda A. Construindo um novo léxico dos direitos humanos: Convenção sobre os direitos das Pessoas com Deficiências. Sur: Rev. Int. de Direitos Humanos 2008; 5(8):43-59.

22. World Health Organization/The World Bank. World report on disability. 2011 [acessado 2011 jul 25]. Disponível em: http://www.who.int/disabilities/world_ report/2011/report/en/index.html.

Artigo apresentado em 15/09/2011

Aprovado em 20/10/2011

Versão final apresentada em 16/11/2011 